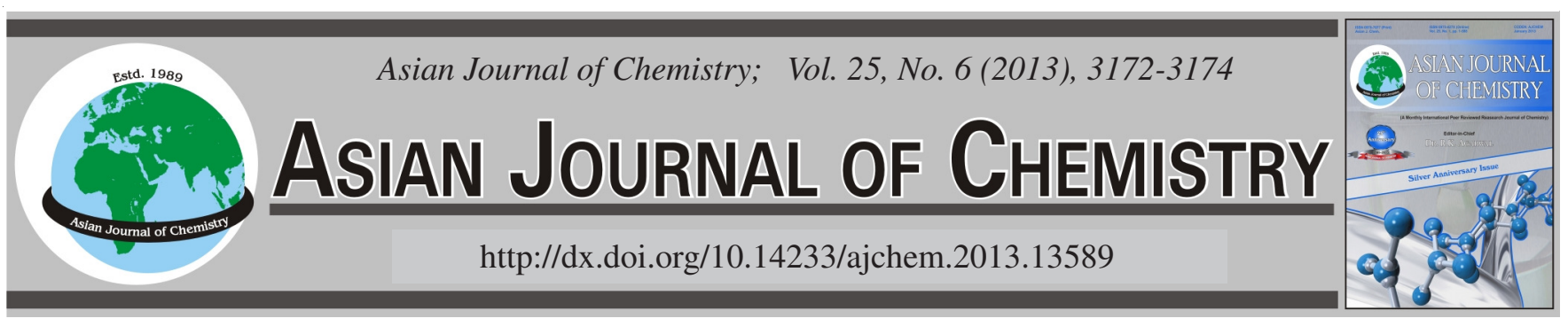

\title{
Preparation of Silica Gel G Loaded Nano-barium Titanate and Its Adsorption Capability to Zinc in Water
}

\author{
Dong ZHANG ${ }^{1, *}$ and YAN CHENG ${ }^{2}$
}

${ }^{1}$ School of Environmental and Chemical Engineering, Shenyang Ligong University, Shenyang 110159, P.R. China

${ }^{2}$ Calibration and Testing Center of Liaoshen Industry Group Co. Ltd., Shenyang 110045, P.R. China

*Corresponding author: Fax: +86 24 24680345; Tel: +86 24 24680345; E-mail: sylgdxdong@ sina.com

(Received: 13 February 2012;

Accepted: 14 December 2012)

AJC-12542

\begin{abstract}
The silica gel G loaded nano-barium titanate (SBT) was prepared by citric acid complex sol-gel method and then its structure and adsorption capability to zinc ion in water were investigated. The results showed that the nano-barium titanate prepared sol-gel method could be steadily loaded on the surface of silica gel $\mathrm{G}$ to produce a cocoon particle adsorption material. This adsorbent had strong absorption capacity to zinc ion in water at $\mathrm{pH} \mathrm{4-8}$ and the static absorption capacity was up to $43.5 \mathrm{mg} / \mathrm{g}$. Zinc ion adsorbed to the adsorbent could be totally eluted by $0.5 \mathrm{~mol} / \mathrm{L}$ nitric acid and then determined by flame atomic absorption spectrometry. The detection limit of this method was $0.5 \mu \mathrm{g} / \mathrm{L}$. The RSD was $2.2 \%$ for six independent adsorptions and determinations of zinc ion with initial concentration of $10 \mu \mathrm{g} / \mathrm{L}$. The method has been applied to the enrichment and determination of trace zinc ion in water with the recovery of 94.9-105.6\%.
\end{abstract}

Key Words: Nano-barium titanate, Silica gel G, Adsorption, Enrichment, Zinc, Flame atomic absorption spectrometry.

\section{INTRODUCTION}

At present, the determination method of zinc mainly includes atomic absorption spectrometry and dithizone spectrophotometry. The reagents used in dithizone spectrophotometry can pollute environment and have some adverse effects on human health. The atomic absorption method has no pollution and can meet the analytical requirements for routine analysis, but it needs pre-enrichment and separation for the samples with low content or high salt ${ }^{1}$. Nano-barium strontium titanate powder had been employed for the adsorption and determination of heavy metal ions in water ${ }^{2-5}$. However, since nanobarium strontium titanate powder is too costly, this restricts its application in practice. Compared with barium strontium titanate, barium titanate is low-cost for preparing sources, but nano-barium titanate particle is similar to nano-barium strontium titanate powder in that the particles are easily conglobated and hardly deposited. Moreover, it was difficult to recycle, limiting its practical application. By fixation of nanopowder was an effective method to solve the problem of recovery ${ }^{6-8}$. In this paper, barium titanate based on silicon gel $G$ was prepared by complex sol-gel method with barium nitrate, tetrabutyl titanate and citric acid. The adsorption properties of barium titanate based on silicon gel $\mathrm{G}$ to zinc ion in water were investigated systemically. Besides, the optimal adsorption and desorption conditions were obtained. This reagent was applied to the enrichment and determination of trace zinc in pure water, well water and tap water.

\section{EXPERIMENTAL}

WYX9003A atomic absorption spectrophotometer (Shenyang Analytical Instrument Factory); S3400N scanning electronic microscope (Hitachi, Japan); X' Pert Pro X-ray diffractometer (PANalvtical B.V., Netherlands).

Silicon gel G (granularity of 10-40 um): For thin-layer chromatography, chemically pure with mass fraction of calcium sulfate of $12-14 \%$, provided by Qingdao Haiyang Chemical Co. Ltd.

Standard stock solution of zinc: $0.1 \mathrm{~g} / \mathrm{L}$; Into a $250 \mathrm{~mL}$ beaker, $0.1000 \mathrm{~g}$ of high-pure metal zinc and $20 \mathrm{~mL}$ of HCI (6 $\mathrm{mol} / \mathrm{L}$ ) were added. The solution was heated to dissolve the sample completely. After cooling, it was diluted to a $1000 \mathrm{~mL}$ volumetric flask. The prepared solution was diluted to the required concentration when used. Water at different $\mathrm{pH}$ was prepared on $\mathrm{pH}$-meter with diluted nitric acid or ammonia water.

All the reagents were analytically pure except for special remarks. The water in this study was distilled water.

Synthesis of loaded nano-barium titanate: According to the method $^{9}$, tetrabutyl titanate was put into excessive water 
under acute stirring to produce white precipitate. After washing, the generated precipitation was dissolved into citric acid-hydrogen peroxide solution. The $\mathrm{pH}$ was adjusted to 6 with ammonia. The solution was kept at $60^{\circ} \mathrm{C}$ for $0.5 \mathrm{~h}$ under stirring to produce stable precursor solution of titanium. Barium nitrate was weighed in a ratio of $n(B a): n(T i)=1: 1$. The sample was dissolved into water at $\mathrm{pH} 6$ to produce stable precursor solution of barium. The precursor solutions of titanium and barium were mixed and kept at $60^{\circ} \mathrm{C}$ for $0.5 \mathrm{~h}$ under stirring to produce barium titanate sol.

The silicon gel $\mathrm{G}$ was immersed with $6 \mathrm{~mol} / \mathrm{L} \mathrm{HCl}$. After suction filtration, the precipitation was washed with water until there was no $\mathrm{Cl}^{-}$anymore and then dried at $110{ }^{\circ} \mathrm{C}$ for $2 \mathrm{~h}$. It was immersed into the prepared barium titanate solution and stirred for $10 \mathrm{~min}$, the mixture was poured on micromesh and then dried at $110{ }^{\circ} \mathrm{C}$. The operation was repeated for three times. The dried sample was put into a crucible and burned at $900{ }^{\circ} \mathrm{C}$ for $2 \mathrm{~h}$. Then, it was stored in desiccator and then cooled to room temperature. The obtained barium titanate based on silicon gel G (SBT) was reserved for use.

Static adsorption tests: A certain amount of $\mathrm{Zn}^{2+}$ was sampled into a $10 \mathrm{~mL}$ calibrated colourimetric cylinder with plug and then diluted to the mark with water at $\mathrm{pH}$ 5. Then, $0.05 \mathrm{~g}$ of SBT was added. After that, the plug was covered and the cylinder was shaken for $5 \mathrm{~min}$. The content of $\mathrm{Zn}^{2+}$ in supernatant fluid was determined and the absorption capacity was calculated.

Elution experiment: According to section static adsorption tests, the supernatant fluid was abandoned. The precipitation was washed with water at $\mathrm{pH} 5$ for twice. $5 \mathrm{~mL}$ of elution agent was added and shaken for $2 \mathrm{~min}$. The content of $\mathrm{Zn}^{2+}$ in elution solution was determined to calculate the recovery.

\section{RESULTS AND DISCUSSION}

From the X-ray diffraction patterns of silica gel before and after it was loaded with barium titanate (Fig. 1), it could be seen that the silica gel $\mathrm{G}$ (Fig. 1a) was non-crystal and showed a non-crystal peak near $22^{\circ}(2 \theta)$. After barium titanate was loaded (Fig. 1b), this peak weakened and a diffraction peak of barium titanate crystal arose (Fig. 1c), indicating that the surface of silica gel $\mathrm{G}$ was covered with a thick layer of barium titanate crystal.

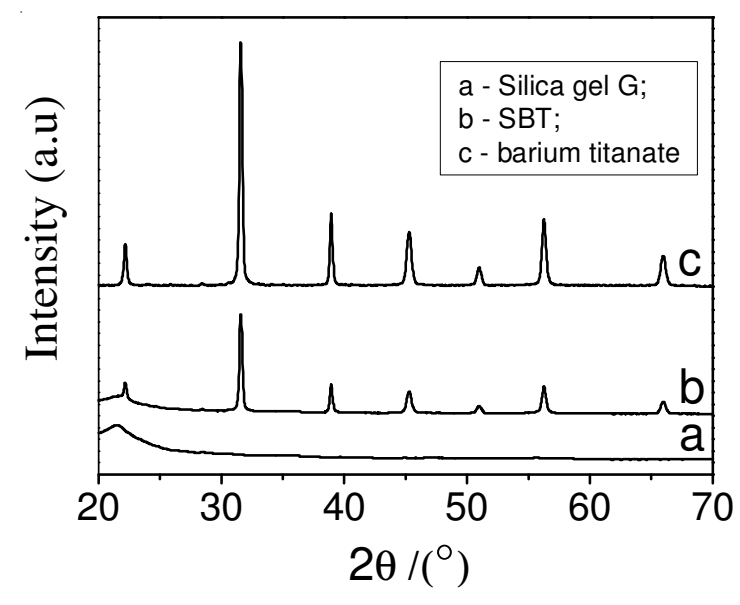

Fig. 1. XRD patterns
Based on the method of XRD full width at half maximum (HFMW) and Scherrer equation $(\mathrm{D}=\mathrm{K} \lambda /(\beta \cos \theta)$, the average grain size of barium titanate crystal could be obtained $(20 \mathrm{~nm})$ by selecting the highest diffraction peak as objective ${ }^{2}$, where, $\mathrm{K}=0.89, \lambda=0.154178 \mathrm{~nm}, \beta$ was full width at half maximum and D was the average grain size of crystal (nm).

Fig. 2 represented the SEM images of silica gel G (Fig. 2a) and SBT (Fig. 2b). It could be clearly seen that after loaded with nano-barium titanate, the surface of silica gel $\mathrm{G}$ exhibited a thick layer of tiny crystal grains.
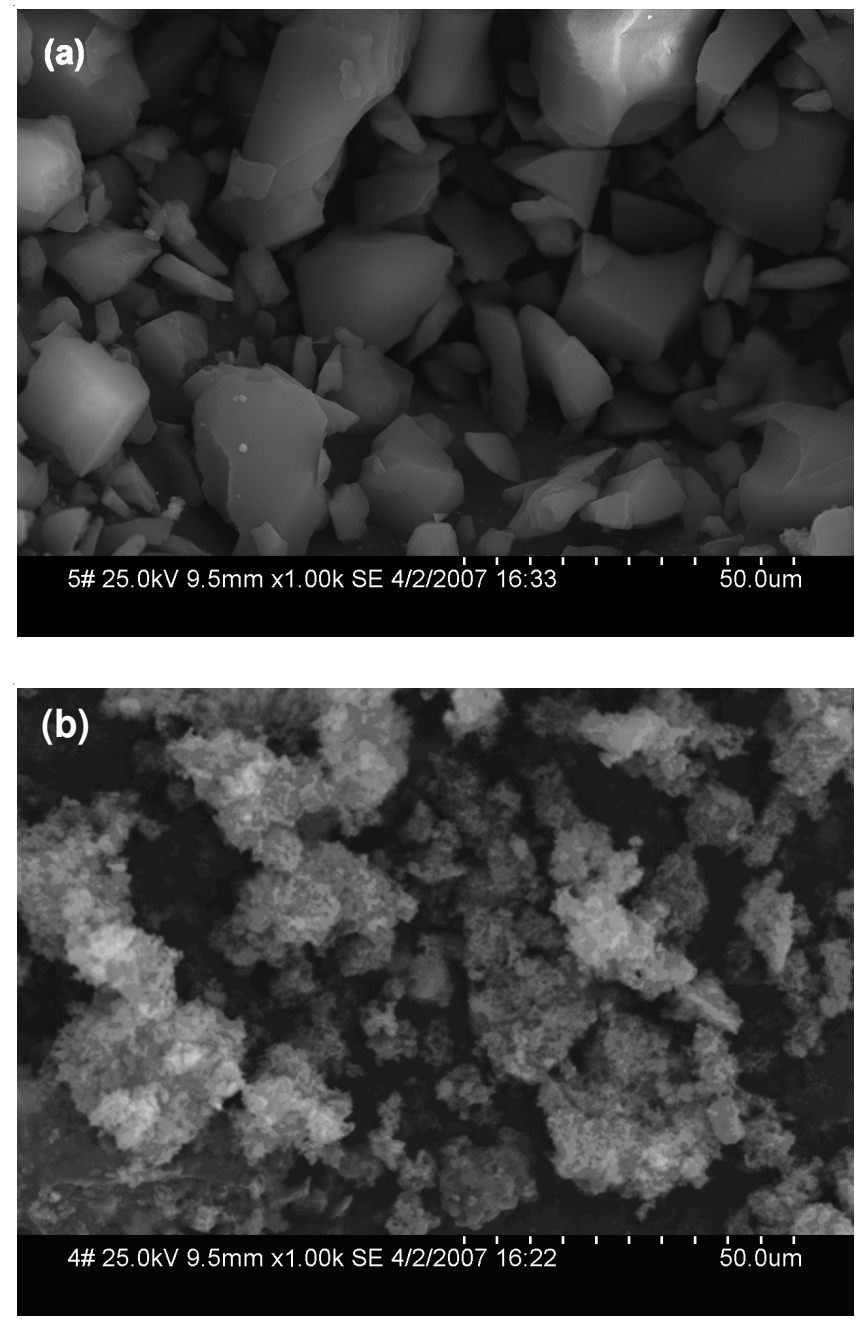

Fig. 2. (a) SEM image of silica gel G; (b) SEM image of SBT

Calculation of loading capacity: By dividing the added mass of SBT to the mass of silica gel G, the loading capacity of loaded nano-barium titanate could be obtained: $570 \mathrm{mg} / \mathrm{g}$.

\section{Static adsorption test}

Effect of $\mathrm{pH}$ and oscillation time on the adsorption of $\mathbf{Z n}^{2+}$ : $0.2 \mathrm{mg}$ of $\mathrm{Zn}^{2+}$ was sampled into a centrifugal tube. After the $\mathrm{pH}$ was adjusted, the solution was diluted to $10 \mathrm{~mL}$ with water at different $\mathrm{pH}$. The adsorption percentage of SBT to $\mathrm{Zn}^{2+}$ was measured. Meanwhile, the adsorption capacities of silica gel $\mathrm{G}$ before and after burning in different $\mathrm{pH}$ mediums were also measured.

The results showed that the silica gel $\mathrm{G}$ before and after burning in all $\mathrm{pH}$ mediums did not adsorb the $\mathrm{Zn}$ ion, while 
SBT had strong adsorption percentage to $\mathrm{Zn}^{2+}$ in the range of pH 4-8 (Fig. 3). In this study, pH 5 was used.

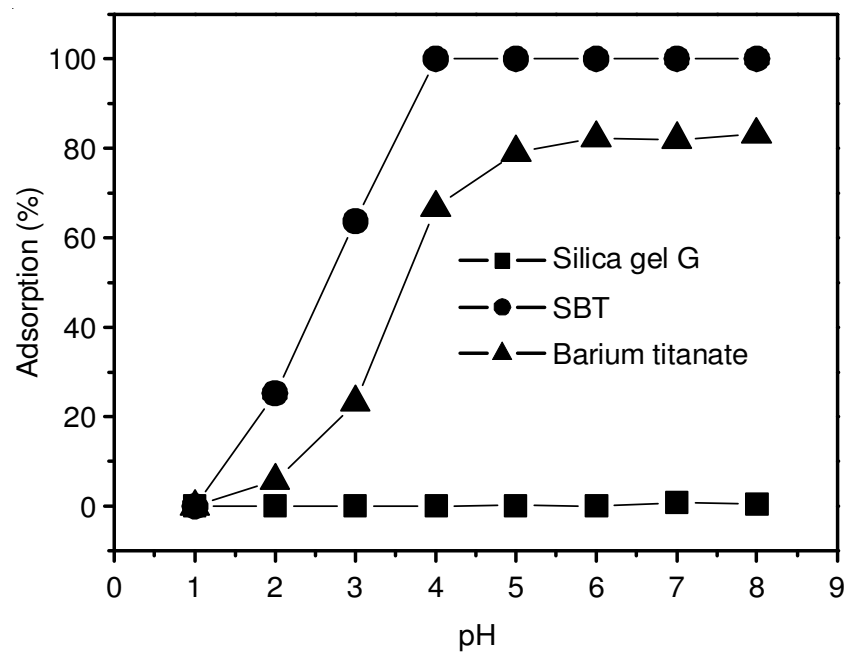

Fig. 3. Effect of $\mathrm{pH}$ on the adsorption percentage

At pH 5, the equilibrium was achieved when the oscillation time was $5 \mathrm{~min}$. The increase of oscillation time had little influence on the adsorption percentage. Therefore, the oscillation time was 5 min in this study.

Stability of elution condition and adsorption agent: It could be seen from Fig. 3 that the adsorption percentage of $\mathrm{Zn}^{2+}$ on SBT was low at $\mathrm{pH}$ 1. Therefore, the adsorbed $\mathrm{Zn}^{2+}$ could be eluted by high-concentration acid. $5 \mathrm{~mL}$ of $0.5 \mathrm{~mol} / \mathrm{L}$ nitric acid was used as the elution agent in this study. When the oscillation-elution time was $2 \mathrm{~min}$, the adsorbed $\mathrm{Zn}^{2+}$ could be eluted completely. The SBT was reused for five times and the recovery could be maintained.

Static adsorption capacity: According the experimental method, when the concentration of $\mathrm{Zn}^{2+}$ was $100 \mathrm{mg} / \mathrm{L}$, the static adsorption capacity of SBT was $43.5 \mathrm{mg} / \mathrm{g}$. The adsorption capacity of SBT to $\mathrm{Zn}^{2+}$ was high and it was an ideal adsorption-enrichment material.

Enrichment factor, detection limit and precision: In order to investigate the enrichment of SBT to $\mathrm{Zn}^{2+}$ in water, a $500 \mathrm{~mL}$ calibrated mark Erlenmeyer flask with plug was used to replace the centrifugal tube. The solution was diluted to $300 \mathrm{~mL}$ with water at $\mathrm{pH} 5$ and $0.5 \mathrm{~g}$ of SBT was added. Then, the adsorbed $\mathrm{Zn}^{2+}$ was eluted with $5 \mathrm{~mL}$ of elution agent. The determination recoveries were all above $96 \%$. Through 60fold of enriching with SBT, the detection limit of this method was $0.5 \mu \mathrm{g} / \mathrm{L}$. For $10 \mu \mathrm{g} / \mathrm{L}$ of $\mathrm{Zn}^{2+}$, the relative standard deviation (RSD, $\mathrm{n}=6$ ) was $2.2 \%$.

Effect of coexisting ions: Different amounts of ions were added into a $150 \mathrm{~mL}$ conical flask containing $5 \mu \mathrm{g}$ of $\mathrm{Zn}^{2+}$. The solution was diluted to $50 \mathrm{~mL}$ with water at $\mathrm{pH} 5$ and then $0.1 \mathrm{~g}$ of SBT was added. The tolerant amount of coexisting ions was defined as resulting in error of $\pm 5 \%$ and was listed as follows (mg): $\mathrm{Na}^{+}, \mathrm{K}^{+}, \mathrm{NH}^{4+}, \mathrm{Cl}^{-}, \mathrm{NO}_{3}{ }^{-}(50) ; \mathrm{Mg}^{2+}, \mathrm{PO}_{4}{ }^{3-}$, $\mathrm{Cd}^{2+}, \mathrm{Cr}(\mathrm{VI}), \mathrm{Pb}^{2-}(10) ; \mathrm{Fe}^{3-}, \mathrm{Ni}^{2+}, \mathrm{Co}^{2+}, \mathrm{Cr}(\mathrm{III}), \mathrm{Ca}^{2+}(5) ; \mathrm{Al}^{3+}$ (2) $; \mathrm{Ag}^{+}, \mathrm{Cu}^{2+}(1)$.

Analytical application: After $\mathrm{pH}$ was adjusted to 5, proper water samples was added into a $150 \mathrm{~mL}$ conical flask, The solution was diluted to $50 \mathrm{~mL}$ with water at $\mathrm{pH} 5$, with $0.1 \mathrm{~g}$ of SBT added. Then, the determination was conducted according to the experimental method. Meanwhile, the recovery test was conducted and compared with dithizone photometry (Table-1). The recoveries of this method were 94.9 to $105.6 \%$. The determination results were in good agreement with those obtained by dithizone spectrophotometry.

\begin{tabular}{|c|c|c|c|c|c|}
\hline \multicolumn{6}{|c|}{$\begin{array}{c}\text { TABLE-1 } \\
\text { DETERMINATION RESULTS OF ZINC ION } \\
\text { IN WATER SAMPLES (mg/L) }\end{array}$} \\
\hline Samples & Found & Added & Recovered & $\begin{array}{c}\text { Recovery } \\
(\%)\end{array}$ & $\begin{array}{l}\text { Found by } \\
\text { dithizone } \\
\text { spectrophotometry }\end{array}$ \\
\hline \multirow{3}{*}{$\begin{array}{l}\text { Well } \\
\text { water }\end{array}$} & & 0.0100 & 0.0461 & 102.0 & \multirow{3}{*}{0.0342} \\
\hline & 0.0359 & 0.0500 & 0.0836 & 95.4 & \\
\hline & & 0.1000 & 0.1308 & 94.9 & \\
\hline \multirow{3}{*}{$\begin{array}{l}\text { Pure } \\
\text { water }\end{array}$} & & 0.0100 & 0.0203 & 97.0 & \multirow{3}{*}{0.0114} \\
\hline & 0.0108 & 0.0500 & 0.0634 & 105.6 & \\
\hline & & 0.1000 & 0.1079 & 97.3 & \\
\hline \multirow{3}{*}{$\begin{array}{c}\text { Tap } \\
\text { water }\end{array}$} & & 0.0100 & 0.0936 & 101.0 & \multirow{3}{*}{0.0865} \\
\hline & 0.0835 & 0.0500 & 0.1315 & 96.0 & \\
\hline & & 0.1000 & 0.1882 & 104.7 & \\
\hline
\end{tabular}

\section{Conclusion}

According to the experimental work, it could be concluded that silica gel G loaded nano-barium titanate(SBT) was prepared by citric acid complex sol-gel method and used for zinc ion adsorption when the $\mathrm{pH}$ value was $4-8$, when the adsorption time was $5 \mathrm{~min}$ and capability of adsorption was $43.5 \mathrm{mg} / \mathrm{g}$. The zinc ion adsorbed on the SBT could be completely eluated by using $5 \mathrm{~mL}$ of $0.5 \mathrm{~mol} / \mathrm{L}$ nitric acid. The detection limit of this method for zinc ion was $0.5 \mu \mathrm{g} / \mathrm{L}$. The proposed method has been applied to the determination of trace amounts of zinc ion in pure water, well water and tap water with satisfactory results.

\section{REFERENCES}

1. State Environmental Protection Administration of China. Analysis Method of Water and Waste Water, China Environmental Science Press, Inc. Beijing, edn. 4 (2002).

2. H.D. Su and D. Zhang, J. Chem. Ind. Eng., 57, 2892 (2006).

3. D. Zhang, H.D. Su and H. Gao, Metal. Anal., 27, 7 (2007).

4. D. Zhang, H.D. Su and H. Gao, Spectrosc. Spect. Anal., 28, 218 (2008).

5. D. Zhang, Asian J. Chem., 24, 5219 (2012).

6. D. Zhang, W.J. Zhang, X. Guan, H. Gao and H.B. He, Spectrosc. Spect. Anal., 29, 824 (2009).

7. D. Zhang, Z.-G. Yuan, X. Guan, W.-J. Zhang, Rare Metal Mater. Eng., 38, 2207 (2009).

8. Y. Liu, P. Liang and L. Guo, Talanta, 68, 25 (2005).

9. Z. Wang, S.L. Jiang, G.X. Li, M.P. Xi and T. Li, Ceram. Int., 33, 1105 (2007). 